\title{
The Application of Multimedia Technology in College English Reading Teaching---A Survey Based on Language Learning Strategies
}

\author{
Fang Guo ${ }^{1, *} \&$ Xin-rui $\mathrm{Wu}^{1}$ \\ ${ }^{1}$ College of Foreign Languages, North China Electric Power University, Beijing, China \\ *Correspondence: College of Foreign Languages, North China Electric Power University, Beijing 102200, China. \\ E-mail: gf922@163.com \\ This paper is funded by North China Electric Power University Teaching Research Project.
}

\author{
Received: April 21, 2019 Accepted: May 27, 2019 Online Published: June 28, 2019 \\ doi:10.5430/ijelt.v6n2p27 URL: https://doi.org/10.5430/ijelt.v6n2p27
}

\begin{abstract}
This study investigates the application of multimedia in college English reading teaching in Beijing University of Agriculture based on language learning strategies. The study finds out that although with the assistance of multimedia technology the current College English reading teaching works well in arousing students' interest in reading and mobilizing students' memory strategies in the classroom, there are still many drawbacks in the current Multimedia-assisted College English reading teaching. This study points out the drawbacks of multimedia teaching first and then proposes corresponding solutions meaning to arouse teachers' reflection on multimedia English teaching mode and enhance the effective use of multimedia technology in English classroom.
\end{abstract}

Keywords: multimedia teaching, English class, English reading teaching, learning strategy

\section{Introduction}

English reading is the basis of listening, speaking, writing and translating skills in English learning, and it is also a crucial part in College English teaching. English reading teaching is related to the effectiveness of English classroom, and then affects students' English level. (Xu, 2017) Since the 1990s, with the development of modern education technology and the implementation of new curriculum reform, multimedia-assisted English reading teaching has been widely used in Colleges and universities. How effective is college English reading teaching assisted by multimedia technology? What are the problems? How to give full play to the powerful function of multimedia technology in College English reading class? In order to test learners' adaptation to the multimedia teaching environment and the effect of multimedia teaching, we investigate the teaching of College English reading in Beijing University of Agriculture and analyze the results under the guidance of learning strategies. We hope that this survey can provide some help for multimedia technology to play its role effectively in College English reading teaching.

The study of second language learning strategies sprang up in the middle and late twentieth century abroad. Most scholars studied learning strategies from the macro perspective. For example, Rigney (1978), Duffy (1982) studied of the definition of learning strategy structure; Moely (1969), Simpson (1994) researched on the learning strategies for empirical research. Zimmerman (1989), Newman (1990), Quince (2013) and other scholars have studied the relationship between learning strategies and self-monitoring. In China, the study of second language learning strategies began in the 1980s. Relevant scholars have made some achievements in this field. For example, Liu Jinkai (2002) and Xu Yulong (2003) studied of the relationship between reading strategies and reading ability; Wang Qiang and Wang Lifei (2004) researched on various factors affecting L2 learning strategies and the positive and negative effects of environmental and learner factors; Xu Jinfen and Nie Rui (2016) investigated the English competence of Chinese university freshmen enrolled in 2014 by strategy inventory. However, at home and abroad, there are not many scholars who study English reading teaching under multimedia environment in China based on learning strategies. For teachers and students in 21s, multimedia teaching is the inevitable result because of the progress of technology and the development of modern education. To solve the problems existing in multimedia English teaching is particularly important for foreign language teaching in today's era. Based on language learning strategies, the author investigates the multimedia reading teaching of College English in Beijing University of Agriculture by 
using quantitative research methods. The study aims at providing some help for the effective application of multimedia technology in English classroom.

\section{Experimental Study}

This survey adopts quantitative research method to investigate the multimedia application in college English reading teaching in Beijing University of Agriculture.

\subsection{Research Questions}

With the help of language learning strategies, we mainly study the current situation of multimedia English reading teaching. The research questions are as follows: What is the effect of Multimedia-assisted College English reading teaching? Which learning strategies have students mobilized in the multimedia reading teaching environment? What are the problems? How can the multimedia technology work more efficiently in College English reading class?

\subsection{Subjects of Investigation}

The subjects of this study are 40 sophomores of non-English majors in Beijing University of Agriculture. They come from different provinces of China, with 20 male and 20 female each. They are all from the departments of science and have similar English learning backgrounds. The content of the college English reading course is Active reading: The Lonely American, Unit 5 from New Horizons College English Comprehensive Course 3. The motivation for this selection is that : college English teaching is only conducted in freshmen and sophomores. Under the influence of "teacher-centered" teaching mode in middle school English teaching, freshmen have not yet formed an objective evaluation of College English teaching while sophomores have their own views on teaching, who can objectively reflect teachers' teaching situation in multimedia environment, and help us to investigate the effect of College English reading teaching in multimedia environment.

\subsection{Data Collection}

This survey collects data through questionnaires and multimedia English reading classroom effectiveness tests.

\subsubsection{Questionnaires}

Learning strategies refer to the specific actions taken by learners in order to make learning easier, faster, happier, autonomous and more adaptable to the new environment (Oxford, 2008). Oxford divides learning strategies into six parts: memory strategy, cognitive strategy, compensation strategy, metacognitive strategy, affective strategy and social strategy. Every part is very important for learners to learn English.

The questionnaire is based on the Strategy Inventory for Language Learning (SILL) developed by Oxford (1990). The questionnaire is divided into six parts: memory strategy, cognitive strategy, compensation strategy, metacognitive strategy, affective strategy and social strategy. Based on the six English learning strategies, the questionnaire analyses the application of college students' English reading learning strategies in multimedia teaching environment, and then tests the effect of College English reading teaching assisted by multimedia. The questionnaire uses Likert Scale's five-point scoring method. According to the questions raised, the subjects could choose five options: complete non-conformity, non-conformity, uncertainty, basic conformity and complete conformity. The greatest advantage of the scale lies in its reliability and validity. Oxford (1996) research shows that SILL has a reliability of between .86 and .91 when applied to second language and foreign language learners. For foreign language learners, translating the scale into their own mother tongue has a higher reliability, reaching the range of .91 to .94 (Cui,2008).

\subsubsection{Effectiveness Test of Multimedia English Reading Classroom}

In order to ensure the correctness and relevance of the exercises, this test is selected from New Horizons College English Comprehensive Course 3. The purpose of this test is to test students' mastery of College English reading under the multimedia teaching environment. The test consists of three parts: vocabulary, grammar and understanding the general idea of the text, totaling 15 points.

\subsection{Data Collection Process}

In order to test the reliability and validity of the questionnaire, several questionnaires were sent out for a small-scale experimental study. After several revisions of the questionnaire and the test questions, the final questionnaire and the test questions were used to complete the whole survey. Questionnaires and tests were conducted anonymously. Students use classroom time to fill in questionnaires and take them back within the prescribed time. All valid questionnaire data and reading test scores were input into the computer, and the data were analyzed by SPSS 
software.

\section{Results and Discussions}

After eliminating the invalid questionnaires, 35 valid questionnaires and test results were obtained. The results of 35 questionnaires were statistically processed, and the mean and standard deviation representing the frequency of each strategy were obtained. The results are presented in Table 1. Next, the mobilization of six general strategies was calculated, and the results are listed in Table 2. Finally, the results of this test (Table 3) were analyzed to test the effectiveness of multimedia technology in College English reading teaching.

\subsection{Frequency of Learning Strategies Being Mobilized}

The options in the questionnaire are in the form of five grades, which are represented by: total inconsistency $=1$ point, inconsistency $=2$ points, uncertainty $=3$ points, basic coincidence $=4$ points, complete coincidence $=5$ points . If the average value is more than 3.5 , the ability to mobilize students' learning strategies in multimedia environment is stronger.

Table 1. Survey on the Use of Overall Learning Strategies in Multimedia Teaching Environment

\begin{tabular}{lcc}
\hline Learning Strategies & Overall Mean & Overall Standard Deviation \\
\hline Memory Strategy & 3.49 & .83 \\
Cognitive Strategy & 3.37 & .78 \\
Compensation Strategy & 3.79 & .71 \\
Metacognitive Strategy & 3.50 & .63 \\
Affective Strategy & 3.35 & .87 \\
Social Strategy & 3.06 & .92 \\
\hline
\end{tabular}

From Table 1, we can see that under the multimedia technology teaching environment, the overall mean of compensation strategy is the highest, 3.79, approaching the level of basic coincidence. And it's standard deviation is 0.71 , which means the data is stable. This shows that multimedia teaching environment is more beneficial to students to predict the background and content of articles. And students are familiar to use multimedia tools to query text content and words. However, the mean of social strategy is the lowest, 3.06, which is between the level of uncertainty and basic coincidence. This shows that although teachers often use multimedia to teach, students can not voluntarily communicate and cooperate with their classmates and teachers. Teachers' teaching can not get feedback, which hinders the development of multimedia teaching. The other strategies are between 3.35 and 3.50, which indicates that they are often mobilized by multimedia teaching environment. The order of average is metacognitive strategy $>$ memory strategy $>$ cognitive strategy $>$ affective strategy. Next, we will analyze which specific English learning strategies are better mobilized by multimedia teaching methods.

As shown in Table 2, in memory strategies, the mean of the viewpoints that multimedia teaching environment is beneficial to the establishment of new and old knowledge links and the enhancement of memory is greater than 3.5, which indicates that memory strategies are mobilized by multimedia teaching in high frequency; in cognitive strategies, the mean of students communicate or summarize in English consciously are less than 3.1, which indicates that multimedia teaching can not mobilize students' active English learning very well. The mean of students consciously use multimedia to learn English $(\mathrm{M}=3.74, \mathrm{SD}=0.77)$ is high, which shows that most students consciously learn English through multimedia video in multimedia classroom. This is also one of the advantages of multimedia teaching. Multimedia teaching provides us with a variety of external sensory stimulation. It combines reading, listening, visual acuity, spoken English learning process and vividly displays knowledge, which is more conducive to students' acquisition and retention of knowledge (He, 1997). Students think that multimedia teaching can help them create classroom situations $(\mathrm{M}=3.34, \mathrm{SD}=0.96)$ and understand the culture of English-speaking countries $(\mathrm{M}=3.66, \mathrm{SD}=0.95)$; the mean of each item of compensation strategy is very high, which shows that students use multimedia more as a query tool and a predictive tool in multimedia teaching. Through multimedia video, students can predict the content and background of the article more interestingly, and then learn the article better; In metacognitive strategies, the view of concentrated thought is particularly prominent, compared with multimedia pre-planned reading $(\mathrm{M}=3.70, \mathrm{SD}=0.79)$ and arousing reading interest $(\mathrm{M}=3.74, \mathrm{SD}=0.87)$, the mean is 3.14 , and the standard deviation is 0.75 . This shows that in multimedia teaching environment, most students can not concentrate on multimedia devices for a long time, resulting in inefficient classroom and other consequences 
hindering English learning; affective strategies and social strategies are generally used in multimedia environment with a low frequency, with a mean of less than 3.5. The mean of communication with teachers is 3.03 , which is the lowest in social and emotional strategies. This shows that most students are unwilling to share any views on teaching with their teachers, and there are some problems in the process of multimedia teaching, such as large amount of information covered by teaching, fast speed and so on. At present, multimedia teaching does not have the ability to increase the communication between students and teachers, and can not promote the cooperative learning between teachers and students, students and students very well.

Table 2. Survey of the Use of Specific Strategies in Multimedia Teaching Environment

\begin{tabular}{llccc}
\hline $\begin{array}{l}\text { Learning } \\
\text { Strategies }\end{array}$ & \multicolumn{1}{c}{ Specific Strategies } & Item & Mean (M) & $\begin{array}{c}\text { Standard } \\
\text { Deviation (SD) }\end{array}$ \\
\hline \multirow{3}{*}{ Memory } & Establish new and old knowledge links & 1 & 3.57 & 1.02 \\
Strategy & Strengthen memory & 2.4 & 3.59 & .93 \\
& Location memory & 3 & 3.37 & 1.07 \\
& Convenient to review & 5 & 3.46 & 1.13 \\
Cognitive & Learning with multimedia & 6 & 3.74 & .77 \\
Strategy & Conscious communication & 7 & 3.09 & 1.16 \\
& Conscious summary & 8 & 3.43 & .96 \\
Compensation & Understand English national culture & 10 & 2.97 & 1.03 \\
Strategy & Guesire & 11.13 & 3.66 & .95 \\
& Prediction & 12 & 3.03 & .74 \\
Metacognitive & Advance planning & 14 & 3.40 & .99 \\
Strategy & Concentrated thought & 15.16 & 3.70 & 1.07 \\
Affective & Arouse interest & 17.19 & 3.14 & .79 \\
Strategy & Exchange experiences & 18 & 3.74 & .75 \\
& Confidence & 20 & 3.06 & .87 \\
Social Strategy & Communicate with teachers & 21.22 & 3.49 & .94 \\
& Ask the teacher for help & 23.25 & 3.03 & .84 \\
& & 24 & 3.11 & 1.14 \\
\hline
\end{tabular}

\subsection{Effectiveness Test of Multimedia English Reading}

As a means of testing teaching effect, score is particularly important. In order to confirm the role of multimedia teaching in the classroom, we analyzed the test results.

Table 3. Analysis Results of Test Results

\begin{tabular}{lcccc}
\hline Question types & Total score & Mean (M) & $\begin{array}{c}\text { Standard } \\
\text { deviation (SD) }\end{array}$ & Percentage (pass) \\
\hline Vocabulary & 2 & 1.54 & .73 & $68.6 \%$ \\
Grammar & 6 & 3.54 & 1.61 & $51.4 \%$ \\
Reading Comprehension & 7 & 3.60 & 1.53 & $25.7 \%$ \\
Overall result & 15 & 8.69 & 3.00 & $51.4 \%$ \\
\hline
\end{tabular}

The results of Effectiveness Test of Multimedia English Reading are listed in Table 3. The vocabulary items $(\mathrm{M}=$ $1.54, \mathrm{SD}=0.73$ ) scored the highest and the standard deviation is the smallest. This shows that students are actively mobilized through multi-sensory stimulation of multimedia, but the average number of grammar questions $(\mathrm{M}=3.54$, $\mathrm{SD}=1.61)$ and text comprehension questions $(\mathrm{M}=3.60, \mathrm{SD}=1.53)$ is low and the standard deviation is large. This shows that in grammar and text comprehension, students' level is uneven and different. The total score $(\mathrm{M}=8.69$, $\mathrm{SD}=3$ ) is close to passing, but the differences between students are great. In the percentage analysis, we found that the pass rate of Reading Comprehension is the lowest --- 25.7\%. This result shows that under the multimedia 
teaching environment, the biggest problem of reading teaching lies in the teaching of text connotation. At the end of the class, most students still can not really grasp the connotation of the article. Multimedia teaching has brought about great differences in grades, which shows great polarization between students. In addition, the questionnaire survey shows that most students think that multimedia teaching (video, pictures, etc.) can arouse reading interest (M $=3.74, \mathrm{SD}=0.87)$, make them understand the culture of English-speaking countries $(\mathrm{M}=3.66, \mathrm{SD}=0.95)$, and then they can learn the articles better. However, according to the effectiveness test, students can not grasp the connotation of English-speaking countries' culture well. Therefore, it is necessary to point out the problems in multimedia classroom teaching and help teachers optimize multimedia classroom teaching.

\section{Conclusion}

The results show that although the current Multimedia-assisted College English reading teaching is effective in arousing students' interest in reading and mobilizing students' memory strategies in the classroom, there are still many drawbacks that can not be ignored in the current Multimedia-assisted College English reading teaching.

1) multimedia teaching lacks the ability to promote cooperative learning between teachers and students, students and students effectively. Students regard multimedia more as a tool of inquiry and prediction, while teachers regard multimedia teaching more as a tool of replacing textbooks and blackboard writing. They do not realize the correct usage and real significance of multimedia teaching.

2) the large amount of text content displayed by teachers in the courseware prevents most students from concentrating on multimedia instruments for a long time, which makes multimedia teaching lose its vivid.

3) most students think that multimedia technology is helpful to arouse interest in reading and to understand the culture of English-speaking countries. However, the survey shows that most students can not grasp the true meaning of the article, and the students' achievement polarization is serious.

Multimedia technology penetrates into college English classes with the momentum of rapid development. As a result, many teachers still do not know how to apply it effectively. This contradiction has led to the emergence of various problems in multimedia teaching. How to introduce multimedia technology into college English reading class in a better way?

In view of the above findings, we propose the following suggestions for college English reading teaching assisted by multimedia.

\section{a) Group Cooperative Learning in Multimedia Environment}

The main purpose of College English reading teaching is to enable students to form the ability of communicating in English by using language. In multimedia teaching, teachers must follow the student-centered teaching method, so that students can form the ability of autonomous learning with the help of teachers and multimedia tools. With the development of cognitive learning theory, it has been found that cooperation can often achieve twice the result with half the effort when learning advanced cognitive ability. In the classroom, teacher can divide the students into several groups. On the premise of full reading, each group will discuss the current problems, and cooperate to complete the structure, genre, technique, emotion and other learning tasks of the article. In group learning, learners discuss and communicate around the current topic to express their understanding of the problem. In this way, multimedia teaching combines individual learning, collective learning and cooperative learning skillfully (Ma, 2007). In the way of cooperative learning, multimedia teaching can play its real role in helping students form the ability to read independently, not as a substitute for blackboard or dictionary.

b) Applying Multimedia According to Students' Psychological Characteristics

College students' learning psychology is directly related to their learning motivation (Biggs, 1979). Motivation is divided into surface motivation and deep motivation. Surface motivation is usually directly related to one's future, and motivation comes from outside. However deep motivation comes from one's interest in English language or culture itself (Wen, 2007). In the process of multimedia teaching, teachers should adopt the way that surface motivation and deep motivation complement each other in teaching. Only by stimulating students' surface motivation and deep motivation can students actively apply various learning strategies to English learning. Motivation for foreign language learning can be cultivated. First of all, explain the importance of English learning. Teachers can use some examples to show students that college students' English learning is not only for the purpose of obtaining certificates, but also for the practical use in society in the future. In addition, according to the actual requirements of different majors for foreign languages, teachers should formulate corresponding teaching plans and apply 
corresponding teaching methods, requiring students in different major to focus on the different part of listening, speaking, reading, writing and translation (Shi, 2000). With learning motivation, learners can learn more actively in the multimedia environment and focus on learning for a long time.

c) The use of multimedia technology for the purpose of promoting students' Perception and application

What is the purpose of College English reading teaching assisted by multimedia? Is it just to learn the surface meaning of the article? After learning a piece of reading, the students only remember the general story plot, which is the sadness of English reading teaching. Teachers should pay more attention to students' perception and application of English, and cultivate their ability to express themselves in foreign languages. We can grasp the cultivating of foreign language expressive ability from three aspects: one is to recognize and understand foreign language expressive ability itself; the other is to establish the connection mechanism between foreign language form and meaning; the third is to establish the connection mechanism between foreign language expressive communicative idea and realize the connection between foreign language expressive ability and communicative idea ability (Dai, 2004). First, let the students analyze the text from the genre and language framework; then, analyze why the genre author applied the framework and how he would express it if the student was the author; finally, after the simple memory language framework, use multimedia to create scenes for students to apply the language framework. In this way, learners have formed the ability of foreign language expression, and the purpose of promoting students' perception and application of foreign language reading has been achieved.

As is mentioned above, multimedia teaching environment has opened up a new world for English teaching. In order to give full play to the advantages of multimedia teaching, we should explore the conjunction between teachers and multimedia technology and establish corresponding teaching models. Therefore, based on learning strategies and the results of the study, the author explores the disadvantages of multimedia-assisted English reading teaching and the solutions. In practice, it is hoped that it will be enlightening to the teaching of English reading under the multi-media environment, and effectively improve the enthusiasm of students and the effectiveness of classroom teaching.

\section{References}

Biggs, J. B. (1979). Individual differences in study processes and the quality of learning outcomes. Higher Education, 8, 381-94. https://doi.org/10.1007/BF01680526

Cui Gang. (2008). Learning Strategies in Foreign and Second Language Classrooms. Beijing: World Publishing Corporation.

Dai Zhongxin. (2004). Verbal Communicative Competence in a Foreign Language: A Personal Experience Perspective. Beijing Normal University.

He Kekang. (1997). The Significance and Development Tendency of Multimedia Education. Modern Distance Education, 1, 7-12. https://doi.org/10.1016/S0300-483X(00)00434-0

Ma Tiewei. (2007). The Research of Multimedia Application in College English Reading Teaching. Education Exploration, 8, 128-129.

Oxford, R. L. (2008). Language Learning Strategies: What Every Teacher Should Know. New York: Newbury House Publishers/Beijing: World Publishing Cooperation.

Shi Yongzhen. (2000). The Survey Report of College Student's English Learning Motivation. Foreign Language Teaching Abroad, 4, 8-11.

Wen Qiufang. (2001). The Change Rules and Features of English Learner's motivation, notion and strategy. Foreign Language Teaching and Research, 2, 105-110+160.

Xu Zhuoyi. (2017). Apply Multimedia to College English Reading Teaching. Chinese Education Academic Journal, $12,102$. 